\title{
An expedient route to heterocycles through $\alpha$-arylation of ketones and arylamides by microwave induced thermal $S_{\mathrm{RN}} 1$ reactions $\uparrow$
}

\author{
Silvia M. Soria-Castro, Daniel A. Caminos and Alicia B. Peñéñory* \\ Microwave irradiation promotes a quick aromatic nucleophilic substitution by a thermally induced electron \\ transfer process to form new $\mathrm{C}-\mathrm{C}$ bonds by the coupling of aryl radicals and enolate nucleophiles. Diverse \\ 2 -aryl-1-phenylethanones can be prepared by the direct $\alpha$-arylation of acetophenone with different \\ haloarenes. The ketone enolate anion is generated by deprotonation with $t \mathrm{BuOK}$ in DMSO and the \\ reaction is carried out in a closed microwave vessel at $70-100{ }^{\circ} \mathrm{C}$ for $10 \mathrm{~min}$. This simple procedure also \\ allows the synthesis of deoxybenzoin and indole heterocycle derivatives by inter- or intra-molecular ring \\ closure reactions, with moderate to excellent substitution yields.
}

Received 6th January 2014

Accepted 25th March 2014

DOI: $10.1039 / \mathrm{c} 4 \mathrm{ra00120f}$

www.rsc.org/advances good yield; yet, two or more hours of photochemical induction or the use of chemical radical initiators are required.

The selection of liquid ammonia as solvent requires distillation prior to use, which is energy costly and entails a particular careful manipulation. ${ }^{8}$ The development of new synthetic procedures, which implies simple and safer reaction conditions, is always a challenge for organic chemists. Alternatively, there are some examples of thermally induced $S_{\mathrm{RN}} 1 \alpha$-arylation of different aliphatic ketone enolate anions with ArI heating at $25{ }^{\circ} \mathrm{C}$ for $60 \mathrm{~min}$ in DMSO with moderate to good yield. ${ }^{9}$ Nevertheless, under these conditions the enolate anions from aromatic ketones did not react. ${ }^{9}$ In addition, thermal or spontaneous initiated reactions need about $60 \mathrm{~min}$ to proceed at room temperature. We consider that this synthetic pathway could be improved by microwave irradiation and be applied to heterocycles synthesis.

In the last decade microwave-assisted organic synthesis (MAOS) has proved an attractive heating method since this system reduces reaction time, increases yields, and in some cases increases selectivity in comparison with traditional oil bath heating. ${ }^{10}$ There are a few cases of thermally induced $\mathrm{S}_{\mathrm{RN}} 1$ reactions by microwave irradiation for the substitution of activated nitro benzyl derivatives. Thus, Vanelle et al. have reported that $\mathrm{S}_{\mathrm{RN}} 1$ reaction of $p$-nitrobenzyl chloride with 2-nitropropane anion under microwave irradiation with a domestic microwave oven affords very good coupling yields. ${ }^{11}$ ketones afford substitution under photo-stimulation in DMSO or liquid ammonia as solvent (Scheme 1). ${ }^{7}$ These reactions had
INFIQC, Dpto. de Quimica Orgánica, Facultad de Ciencias Químicas, Universidad Nacional de Córdoba, Ciudad Universitaria, X5000HUA Córdoba, Argentina. E-mail: penenory@fcq.unc.edu.ar; Web: http://www.infiqc.fcq.edu.ar

$\dagger$ Electronic supplementary information (ESI) available: Typical reaction profile under microwave irradiation and spectra $\left({ }^{1} \mathrm{H}\right.$ and ${ }^{13} \mathrm{C}$ NMR) for products 6 and 7. See DOI: $10.1039 / \mathrm{c} 4 \mathrm{ra00120f}$

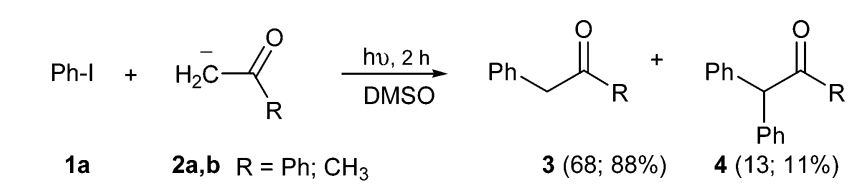

Scheme 1 Photostimulated $\mathrm{S}_{\mathrm{RN}} 1 \alpha$-arylation of ketone enolate anions. 
This early use of a domestic microwave oven did not allow an accurate control of temperature, pressure and power applied to the sample. Today, strict reaction conditions could be set and controlled by specific laboratory microwave devices. In consequence the experiment conditions can be easily reproduced. Recently, Vanelle et al. reported the C-alkylation of 2-nitropropane anion with 4-[4-(chloromethyl)phenyl]-1,2-dimethyl-5nitro- $1 \mathrm{H}$-imidazole at $140{ }^{\circ} \mathrm{C}$ (DMF) or $170{ }^{\circ} \mathrm{C}$ (DMSO) for 30 min in $25 \mathrm{~mL}$ using an accurate multimode microwave reactor with $200 \mathrm{~W}$ of applied power, with $60 \%$ yield $^{12}$ (Scheme 2 ).

In this work, we revisited the thermal initiated- $S_{\mathrm{RN}} 1$ reactions of ArX with enolate nucleophiles, using for first time a controlled microwave heating to promote the reaction. Here we present a new method to produce the $\alpha$-arylation of arylketones and aryl acetamides induced by thermal initiation under microwave irradiation. This methodology has also been successfully applied to the one-pot synthesis of heterocycles.

\section{Results and discussion}

\section{Microwave-induced reactions}

The reaction between $\mathrm{PhI}$ (1) and the enolate anion of acetophenone (2a) was taken as a model to explore the effectiveness of microwave irradiation as heating method for thermal initiation, as a simple alternative to photo-induction in liquid ammonia or DMSO. Table 1 shows the results yielded.

When a mixture of $\mathbf{1}$ and anion $2 \mathrm{a}$ was stirred at $25{ }^{\circ} \mathrm{C}$ for $60 \mathrm{~min}$ in DMSO, the detection of only a trace of $\alpha$-arylation product 3a by GLC was reported (Table 1 , entry 1$){ }^{9}$ In view of this preliminary result we first tested the reaction between PhI with acetophenone enolate anion by heating under microwave irradiation for $10 \mathrm{~min}$ at different temperatures. No reaction at $40{ }^{\circ} \mathrm{C}$ under microwave irradiation was observed; however, by increasing the temperature to $50-60{ }^{\circ} \mathrm{C}$, the substitution product 3a occurred in moderate yields and only traces $(<4 \%)$ of di-arylation product $4 \mathbf{a}$ were observed (Table 1, entries 2-4).

Following this examination, the best result in this system was obtained at $70{ }^{\circ} \mathrm{C}$ in DMSO, irradiated with microwave; substitution product 1,2-diphenylethanone $3 \mathbf{a}$ was quantified in $55 \%$ yield in just $10 \mathrm{~min}$, with a conversion of $78 \%$ determined by iodide ion quantification (Table 1, entry 5). A similar result was found at $5 \mathrm{~min}$; yet the GC-MS analysis showed presence of unreacted $\mathrm{PhI}$ (Table 1, entry 6). Increasing time to $30 \mathrm{~min}$, or raising temperature to $100{ }^{\circ} \mathrm{C}$ did not show a substantial rise in

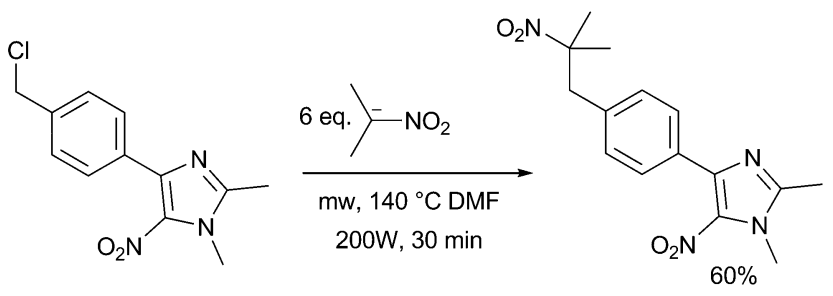

Scheme 2 Fast thermal long distance $\mathrm{S}_{\mathrm{RN}} 1$ reaction of 4-[4-(chloromethyl)-phenyl]-1, 2-dimethyl-5-nitro- $1 \mathrm{H}$-imidazole with 2-nitropropane anion.
Table 1 Temperature effect on microwave-induced $\alpha$-arylation of acetophenone with phenyl halides in $\mathrm{DMSO}^{a}$

\begin{tabular}{|c|c|c|c|c|c|}
\hline \multirow[b]{2}{*}{ Entry } & $\begin{array}{l}\mathrm{Ph}-\mathrm{X} \\
1\end{array}$ & $+\mathrm{H}_{2} \overline{\mathrm{C}}-$ & $\begin{array}{c}\text { microwave } \\
\text { Temp., } 10 \mathrm{~min} \\
\text { DMSO }\end{array}$ & $\underbrace{\mathrm{Ph}}_{3 a}+X$ & \\
\hline & $\mathrm{X}$ & Time (min) & Temp. $\left({ }^{\circ} \mathrm{C}\right)$ & Product $\mathbf{3 a}^{b}(\%)$ & $\mathrm{X}^{-c}(\%)$ \\
\hline $1^{d}$ & I & 60 & 25 & $<1$ & $<1$ \\
\hline 2 & I & 10 & 40 & Trace & n.q. \\
\hline 3 & I & 10 & 50 & 34 & n.q. \\
\hline 4 & I & 10 & 60 & $45^{e}$ & n.q. \\
\hline 5 & I & 10 & 70 & $55^{e}$ & 78 \\
\hline 6 & I & 5 & 70 & $49^{e}$ & 70 \\
\hline 7 & I & 30 & 70 & $54^{e}$ & 72 \\
\hline 8 & I & 10 & 100 & $58^{e}$ & 92 \\
\hline $9^{f}$ & I & 10 & 70 & 7 & $<10$ \\
\hline $10^{g}$ & I & 10 & 70 & 8 & $<10$ \\
\hline 11 & $\mathrm{I}^{h}$ & 10 & 70 & - & 0 \\
\hline 12 & $\mathrm{I}^{i}$ & 10 & 70 & 14 & 21 \\
\hline 13 & $\mathrm{r}^{j}$ & 10 & 70 & $-^{k}$ & 80 \\
\hline 14 & $\mathrm{Br}$ & 10 & 70 & Trace & 4 \\
\hline
\end{tabular}

${ }^{a}$ Reactions heated by microwave irradiation $\left(150 \mathrm{~W}_{\max }\right)$ under $\mathrm{N}_{2}$ atmosphere for $10 \mathrm{~min}$. Acetophenone $(1.5 \mathrm{mmol})$, $t$ BuOK (1.55 $\mathrm{mmol})$, and $\mathrm{PhI}(0.5 \mathrm{mmol})$ in $2 \mathrm{~mL}$ of DMSO, otherwise indicated. ${ }^{b}$ Quantified by NMR with internal standard. ${ }^{c}$ Determined potentiometrically using a $\mathrm{Ag} / \mathrm{Ag}(\mathrm{I})$ electrode. n.q.: no quantified. ${ }^{d}$ Thermostatized in water bath, from ref. $9 .{ }^{e}$ Traces $(<4 \%)$ of diarylation product $4 \mathbf{4 a}$ were observed. ${ }^{f} \mathrm{DMF}$ as solvent. ${ }^{g} \mathrm{MeCN}$ as solvent. ${ }^{h}$ Without acetophenone enolate. ${ }^{i}$ With $10 \mathrm{~mol} \% \mathrm{~m}$ dinitrobenzene. ${ }^{j}$ With $t$ BuOK as nucleophile and base. ${ }^{k} \mathrm{PhOC}\left(\mathrm{CH}_{3}\right)_{3}$ was quantified by NMR in $4 \%$ yield.

the yield of substitution product 3a; however, an increase in the reduction product was shown through the higher iodide ion yield (Table 1, entries 7 and 8). The 1,2-diphenylethanone 3a was stable under the reaction conditions. After GC-MS analysis it did not show any by-product produced by thermal decomposition at $70-80{ }^{\circ} \mathrm{C}$, under microwave heating for $10 \mathrm{~min}$; it was recovered in $84 \%$ isolated yield. All attempts to detect the reduced product benzene were unsuccessful. ${ }^{13}$ Another solvents such as DMF or MeCN were also tried without success (Table 1, entries 9 and 10). In addition, the main reaction by-product was the auto-condensation of acetophenone present in excess in the basic reaction media.

\section{Comparison between microwave and oil bath heating}

The same model reaction was tested using a sealed microwave tube on a pre-heated (to accurate temperature) oil bath, and after $10 \mathrm{~min}$ at $70{ }^{\circ} \mathrm{C}$ only $10 \%$ yield of product 3a was quantified by GC-MS. In addition, product $3 \mathrm{a}$ was obtained in $17 \%$ yield after $60 \mathrm{~min}$ at $70{ }^{\circ} \mathrm{C}$. When the reaction was performed under microwave irradiation in an open vessel (at atmospheric pressure), a comparable yield of $\mathbf{3 a}$ and unreacted $\mathrm{PhI}$ were found in relation to those observed in Table 1, entry 5 . Under microwave irradiation it is possible that significant and localized overheating is produced in the solution since DMSO is a 
strongly microwave absorbing solvent. This overheated spots, will help to accelerate reaction rate in relation to conventional heating. ${ }^{14}$ In addition, the pressure conditions of $1.7 \mathrm{~atm}$ did not seem to be required; however, microwave irradiation was needed to accelerate the reaction. This reaction effectively proceeds faster under microwave irradiation in an open or closed vessel; for security issues, however, the latter was adopted as a standard methodology. Further research into these microwave induced thermal ET reactions is currently in progress in our lab.

\section{Reaction mechanism}

To evaluate the mechanism involved in this reaction, some experiments were performed. First we checked the presence of radical intermediates in the reaction by using 1-(allyloxy)-2iodobenzene (5) as radical clock (Scheme 3$){ }^{15}$ To reduce the base promoted isomerization of the double bond in $\mathbf{5}$, the reaction was conducted at $60{ }^{\circ} \mathrm{C} .{ }^{16}$ Thus, the reaction of 5 with the enolate anion of acetophenone in a ratio $1: 3$, after 10 minutes under microwave irradiation at $60{ }^{\circ} \mathrm{C}$, gave $29 \%$ and $16 \%$ of the cyclized (6) and straightforward (7) substitution products, respectively. This result clearly indicates that aryl radicals are reactive intermediates in the microwave reaction. ${ }^{15}$ Formation of product 6 must involve the intermediacy of the 2-(allyloxy)phenyl radical and its 5-exo ring closure followed by addition to the enolate anion 2a. On the other hand, direct coupling between the 2-(allyloxy)phenyl radical and the anion 2a followed by ET and isomerization of the double bond affords product 7. Isomerization of $\mathbf{5}$ prior to ET step would also account for the formation of product 7 , but would not allow 5-exo cyclization to yield derivative 6 after coupling with the nucleophile. In fact, when the reaction between 5 and anion $2 \mathbf{a}$ was performed at $80^{\circ} \mathrm{C}$, the only product obtained was 7 in $45 \%$ yield. Moreover, PhI showed to be thermally stable under the reaction conditions. After 10 min of microwave irradiation of $\mathrm{PhI}$ in DMSO, either benzene or iodide ion was not detected, (Table 1, entry 11). This fact allows discarding a homolytic rupture of the $\mathrm{C}_{\mathrm{Ar}}-\mathrm{I}$ bond as the radical initiation process. Furthermore, when the reaction between $\mathrm{PhI}$ and the enolate anion of acetophenone was conducted in the presence of $10 \mathrm{~mol} \%$ of $m$-dinitrobenzene, which is a strong electron acceptor inhibiting the ET step, ${ }^{2}$ a $14 \%$ yield of product was obtained with $21 \%$

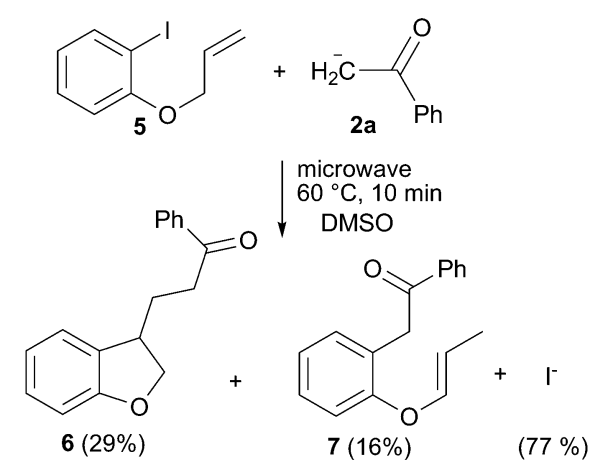

Scheme 3 1-(Allyloxy)-2-iodobenzene as radical clock. conversion yields (Table 1, entry 12). These assays suggest that the reaction proceeds through an $\mathrm{S}_{\mathrm{RN}} 1$ mechanism thermally initiated ${ }^{17}$ with radicals and radical anions as intermediates. In this reaction, the source of initiating electrons could be the nucleophile itself, which transfers an electron to the PhI to generate $\mathrm{Ph}$ radical and $\mathrm{I}^{-}$by a dissociative ET. ${ }^{17,18}$ In this case, the increase in temperature or the direct microwave energy applied to the substrate could provide the necessary energy to the initial ET from the nucleophile to the ArX. Alternatively, the slightly excess of $t \mathrm{BuO}^{-}$anion could also act as the electron donor in an entrainment reaction. ${ }^{19}$ This later statement was confirmed by the reaction between $\mathrm{PhI}$ and $t \mathrm{BuOK}$ in the absence of acetophenone, which gave $80 \%$ of $\mathrm{I}^{-}$anions after 10 min of microwave irradiation (Table 1, entry 13). As in the above reactions, benzene could not be detected after microwave irradiation. In addition only a low amount of the substitution product with the $t \mathrm{BuO}^{-}$anion was observed (4\%), according to the low reactivity of the alkoxide anions toward aryl radicals attributed to their very positive oxidation standard potentials, being hard nucleophiles., ${ }^{2,20}$

Additionally, $\mathrm{PhBr}$ was unreactive toward the anion of acetophenone after $10 \mathrm{~min}$ of microwave irradiation at $70{ }^{\circ} \mathrm{C}$, with low conversion $(<5 \%)$ and traces of the substitution product $3 \mathbf{a}$ (Table 1, entries 14). Similar results were observed at 100 or $140{ }^{\circ} \mathrm{C}$.

Furthermore, the reactivity of dihalobenzenes toward the anion of acetophenone was studied under microwave induction and the results compared with the photoinduced reactions in order to get further insights into the mechanism. The microwave-irradiated reactions of ortho-haloiodobenzenes (8a and $\mathbf{b} ; \mathrm{X}=\mathrm{I}, \mathrm{Br}$ ) with anion $\mathbf{2 a}$ gave mono-substitution with retention of halide (9a and $\mathbf{b}$ ) and mono-substitution with reduction of the second halide (3a), the later only observed for $\mathrm{X}=\mathrm{I}$ (Scheme 4). The reaction of the para-diiodobenzene (8c) with anion 2a afforded both the $p$-iodo substituted derivative (9c) and the mono-substituted reduced product 3a with only trace of the $p$-disubstituted derivative observed by GC-MS. Similar results were previously obtained in the photoinduced reactions of $\mathbf{8 a}$ and $\mathbf{b}$ with anion $\mathbf{2 a}$. $^{21}$ The agreement between the reactions performed under photochemical and microwave irradiation strongly supports that both reactions proceed by the same $S_{\mathrm{RN}} 1$ mechanism as follows. After the initial ET, the radical anion of the substrate (8a and $\mathbf{b}^{-}$) fragments into iodide anion and radical 10a and $\mathbf{b}$. The radical anions $9 \mathbf{a}$ and $\mathbf{b}^{-}$formed by the coupling of radical $\mathbf{1 0 a}$ and $\mathbf{b}$ with anion $\mathbf{2 a}$ can afford the

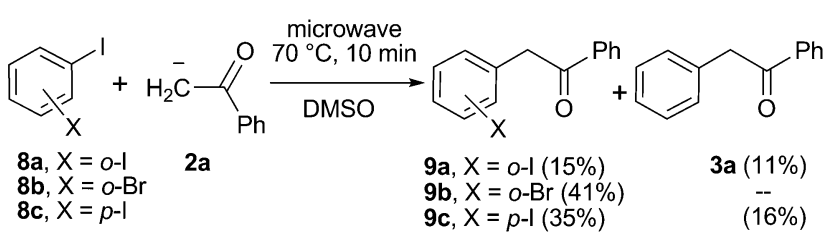

Scheme 4 Microwave-induced reaction of acetophenone anion (2a) with ortho-haloiodobenzene ( $8 \mathrm{a}$ and $\mathbf{b}$ ) and para-diiodobenzene (8c) in DMSO. 
mono-substituted products 9a and $\mathbf{b}$ after inter-ET to the substrate (Scheme 5, pathway a) or can fragment at the $\mathrm{C}$ halogen bond to give radical 11 (Scheme 5, pathway b). The unpaired spin distribution in the most stable radical anion intermediate (9a and $\mathbf{b}^{-}$) is localized in the benzoyl moiety ( $\pi$-system), which is separated from the ortho-halophenyl moiety by a $\mathrm{sp}^{3}$ carbon atom; the intra-ET is favored only when $\mathrm{X}=\mathrm{I}$ to afford radical $\mathbf{1 1}$ after $\mathrm{C}-\mathrm{X}$ fragmentation.

Finally, disubstitution was not observed, even with the orthodiiodobenzene (8a). This can be attributed to the low excess of the acetophenone anion present in the reaction media, since di-substitution was previously observed for the ketone enolate anion under photostimulation in liquid ammonia. ${ }^{22}$ An unfavorable coupling reaction due to steric constraints can also be responsible. On the other hand, trace of disubstitution was detected by GC-MS for the reaction of para-diiodobenzene (8c) in the presence of 3 equivalents of anion $2 \mathbf{a}$, under both microwave and photo-induced reactions.

\section{Scope of the microwave induced $\alpha$-arylation reaction}

We subsequently studied the reactivity of different aryl halides to determine the scope of the microwave $\alpha$-arylation reaction; results are found in Table 2 . In general, the reaction of aryl iodides bearing electron-donor and -acceptor substituent gave the substitution product in moderate to good yields (46-57\%, Table 2, entries 1-4). Using 4-iodobenzonitrile, anion 2a was mono-arylated in $46 \%$ yield. The $\alpha$-arylation of 4 -iodobenzonitrile has not been previously reported under photoinduced $S_{\mathrm{RN}} 1$ conditions. ${ }^{2}$ Furthermore, attempts to $\alpha$-arylation of anion $2 \mathrm{a}$ by Pd-catalysis failed; instead of the desired product, $\beta$-enaminones were obtained by condensation of the acetophenone with the nitrile moiety of the substrate. ${ }^{23}$ On the other hand, it is known that the fragmentation rates of the radical anions of nitro-substituted aryl halides determined electrochemically ${ }^{24}$ or by pulse radiolysis ${ }^{25}$ are slow and range from $10^{-3}$ to $10^{2} \mathrm{~s}^{-1}$. As a consequence such substrates have not been suitable for electrochemical or photoinduced $\mathrm{S}_{\mathrm{RN}} 1$ reactions. ${ }^{2}$ In this context, it should be noted that under microwave irradiation $19 \%$ of the nitro derivate is obtained (Table 2, entry 5). Nevertheless, a classical aromatic nucleophilic substitution cannot be disregarded. In addition, 1-iodonaphtalene, 1-bromonaphtalene, 2-bromonaphtalene and 2-iodopyridine, by reaction with anion 2a gave substitution products in moderate yield (Table 2, entries 6-9).

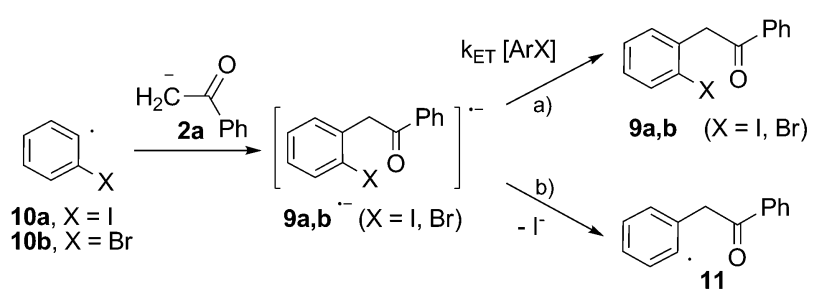

Scheme 5 Propagation steps for the $\mathrm{S}_{\mathrm{RN}} 1$ mechanism of the reaction of acetophenone anion (2a) with ortho-haloiodobenzene ( $8 a$ and $b$ ) in DMSO.
Table 2 Microwave-induced substitution reactions of ArX by the enolate anion of acetophenone in $\mathrm{DMSO}^{a}$

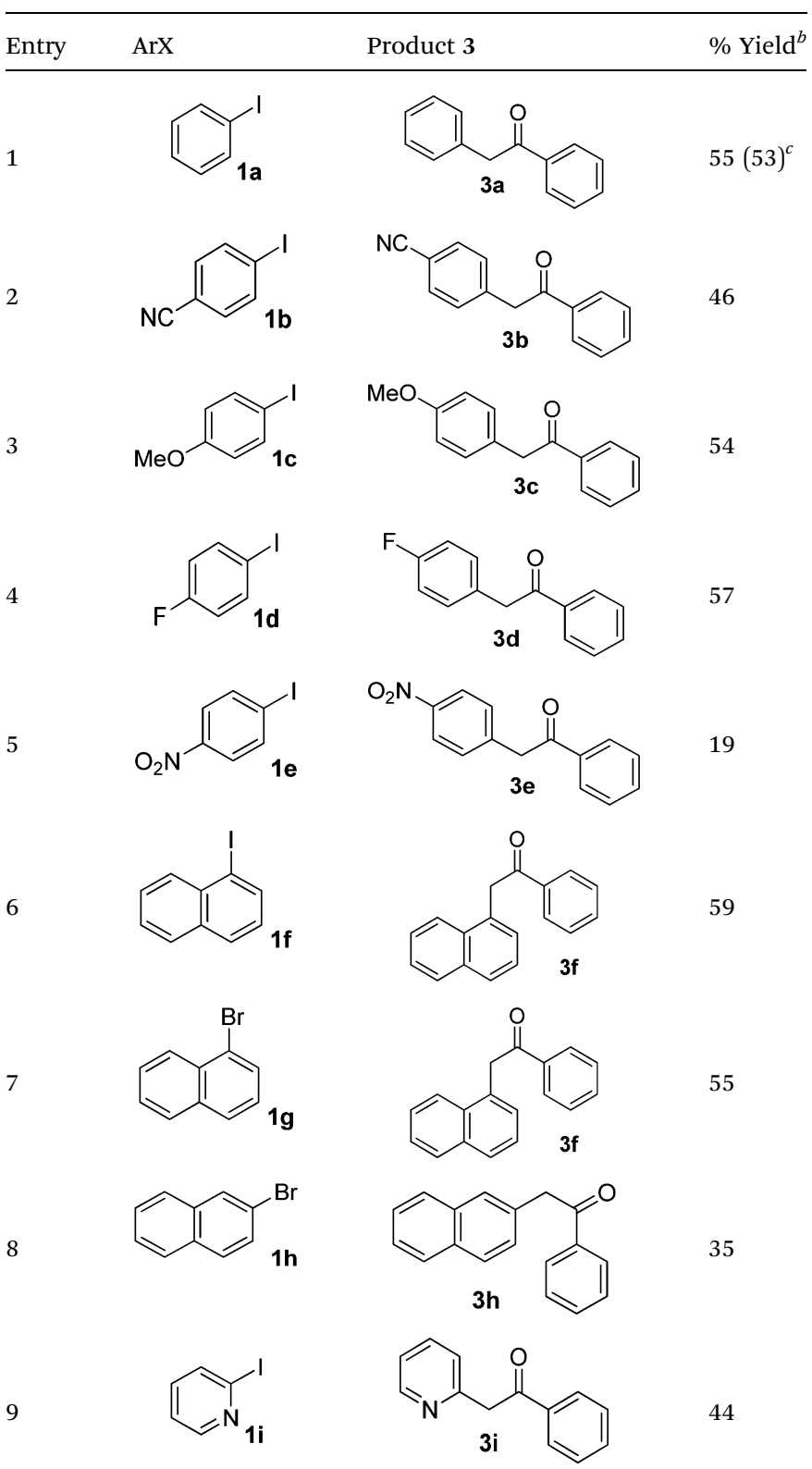

${ }^{a}$ Reactions heated to $70{ }^{\circ} \mathrm{C}$ by microwave irradiation $\left(150 \mathrm{~W}_{\max }\right)$ under $\mathrm{N}_{2}$ atmosphere for $10 \mathrm{~min}$. Acetophenone $(1.5 \mathrm{mmol}), t$ BuOK (1.55 $\mathrm{mmol})$, and ArX $(0.5 \mathrm{mmol})$ in $2 \mathrm{~mL}$ of DMSO, otherwise indicated. ${ }^{b}$ Quantified by NMR with internal standard. ${ }^{c}$ Isolated yield from a preparative scale reaction: acetophenone $(7.5 \mathrm{mmol}), t$ BuOK $(7.75$ $\mathrm{mmol})$, and $\mathrm{PhI}(2.5 \mathrm{mmol})$ in $10 \mathrm{~mL}$ of DMSO.

Besides, $p$-substituted acetophenone enolate anions $(2 \mathbf{j}-\mathbf{m})$ were also investigated as nucleophiles in the reaction with $\mathrm{PhI}$ (Table 3). As expected for an ET-initiated reaction, the presence of an electron donor group such as $\mathrm{CH}_{3}$ in anion $2 \mathbf{j}$ afforded comparable yield of substitution product relative to anion $\mathbf{2 a}$ (Table 3, entries 1 and 2). The amino group is also deprotonated in the reaction media and the yield of $\alpha$-arylation decreased (Table 3, entry 3). On the other hand the presence of electron withdrawing groups such as $\mathrm{Cl}$ and $\mathrm{NO}_{2}$ in the enolate anion 
Table 3 Microwave-induced substitution reactions of $\mathrm{Phl}$ by ketone enolate anions in $\mathrm{DMSO}^{a}$

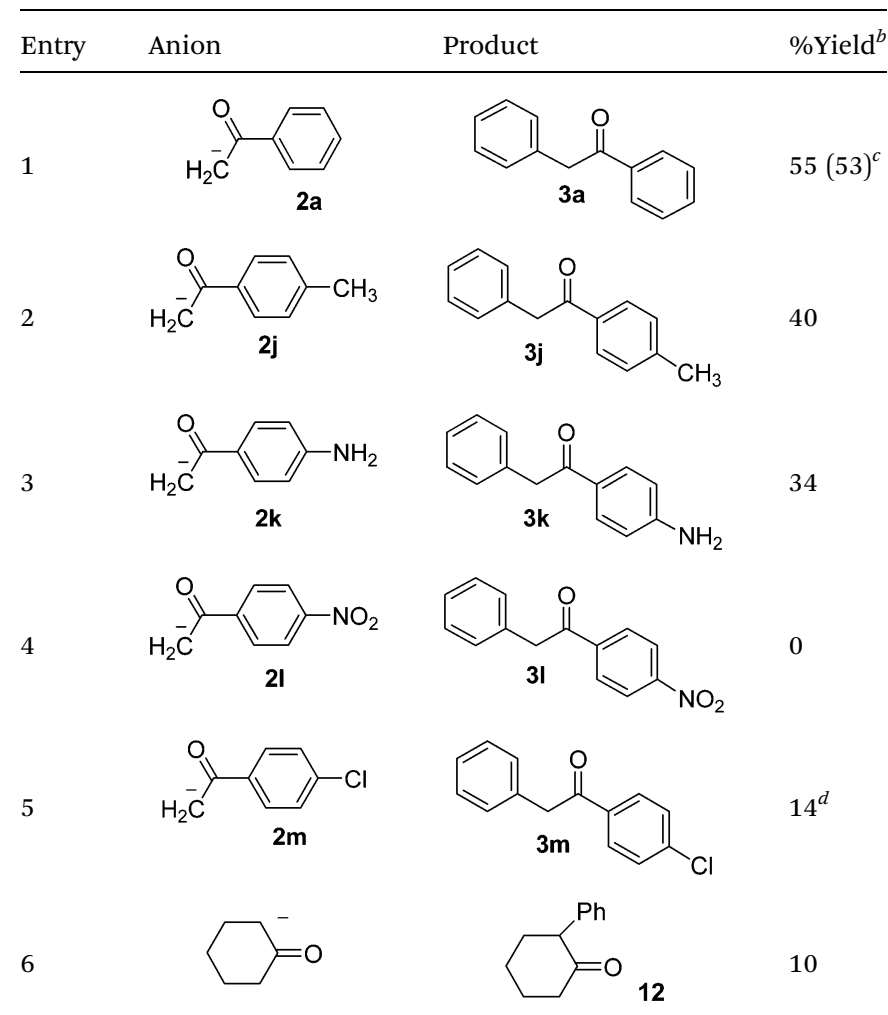

${ }^{a}$ Reactions heated to $70{ }^{\circ} \mathrm{C}$ by microwave irradiation $\left(150 \mathrm{~W}_{\max }\right)$ under $\mathrm{N}_{2}$ atmosphere for $10 \mathrm{~min}$. Ketone (1.5 mmol), $t \mathrm{BuOK}(1.55 \mathrm{mmol})$, and PhI $(0.5 \mathrm{mmol})$ in $2 \mathrm{~mL}$ of DMSO. ${ }^{b}$ Quantified by NMR with internal standard. ${ }^{c}$ Isolated yield from a preparative scale reaction. ${ }^{d}$ Together with $7 \%$ of $3 a$.

Table 4 Synthesis of 1-methyl-3-phenylindolin-2-one (14) by intramolecular cyclization of $\mathrm{N}$-(2-halophenyl)phenylacetamides by microwave heating
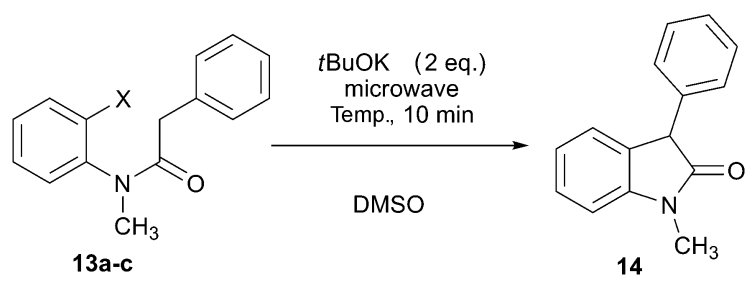

\begin{tabular}{lllcc}
\hline Entry & Substrate 13 & $\mathrm{X}$ & Temp. $^{\circ} \mathrm{C}$ & Product 14 yield $^{a} \%$ \\
\hline 1 & 13a & I & 70 & $90^{b}$ \\
2 & & & 100 & 100 \\
3 & 13b & $\mathrm{Br}$ & 70 & 30 \\
4 & & & 100 & 80 \\
5 & 13c & $\mathrm{Cl}$ & 100 & 0 \\
6 & & & 130 & 14
\end{tabular}

${ }^{a}$ Quantified by GC by the internal standard method. ${ }^{b}$ Together with $10 \% N$-methyl- $N, 2$-diphenylacetamide.

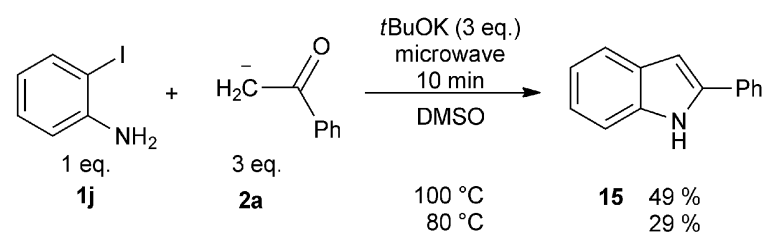

Scheme 6 "One-pot" synthesis of 2-phenylindole (15).

strongly inhibits or avoids ET pathways (Table 3, entries 4 and $5)$. The formation of $3 \mathbf{a}$ in the $\alpha$-arylation of anion $2 \mathrm{~m}$ supports the participation of $3 \mathrm{~m}^{-}$as intermediate (Table 3 , entry 5).

In addition, we have performed some experiments using the enolate anion of cyclohexanone as nucleophile under microwave irradiation to compare with the thermal induced reaction previously reported. ${ }^{9}$ To our surprise at $70{ }^{\circ} \mathrm{C}$ only $10 \%$ of the $\alpha$-arylated product, 2-phenylcyclohexanone (12) was observed and most IPh remained unreacted (Table 3, entry 6). The yield of 12 was not improved by increasing the temperature to $100{ }^{\circ} \mathrm{C}$, except for the ketone condensation product. Further attempts to reproduce the previous reported results ${ }^{9}$ were unsuccessful. In our hands, IPh did not react with the enolate anion of cyclohexanone in DMSO after 60 min heating at $25^{\circ} \mathrm{C}$.

As it has been well established, the photoinduced $\mathrm{S}_{\mathrm{RN}} 1$ reaction provides a good alternative to the synthesis of heterocycles. ${ }^{2}$ Therefore, two different approaches were explored to achieve target compounds under microwave irradiation: (1) intramolecular $\mathrm{S}_{\mathrm{RN}} 1$ reaction and (2) intermolecular $\mathrm{S}_{\mathrm{RN}} 1$ reaction, followed by a polar ring closure reaction. Initially, the synthesis of indolinone derivatives was performed by intramolecular cyclization of $\mathrm{N}$-(2-halophenyl)phenylacetamides (13) under microwave irradiation (Table 4). Thus, the reaction of the iodo derivative 13a in the presence of $t$ BuOK gave $90 \%$ yield of the cyclized compound 1-methyl-3-phenylindolin-2-one (14) and $10 \%$ of the reduced product $N$-methyl- $N, 2$-diphenylacetamide at $70{ }^{\circ} \mathrm{C}$ in DMSO (Table 4, entry 1). Quantitative yield was achieved by increasing temperature to $100{ }^{\circ} \mathrm{C}$ (Table 4 , entry 2). The bromo derivative $\mathbf{1 3 b}$, afforded $80 \%$ of substitution at $100{ }^{\circ} \mathrm{C}$, while the chloro derivative $13 \mathrm{c}$ required increasing temperature to $130{ }^{\circ} \mathrm{C}$ to observe only $14 \%$ of product 14 (Table 4 , entries 3-6). The reactivity order $\mathrm{I}>\mathrm{Br}>\mathrm{Cl}$ is according to the reduction potential of the aryl halides and with the average fragmentation rate constant for their radical anion intermediates. ${ }^{2}$ Finally, this methodology was extended to the "one-pot" synthesis of indole derivatives (15) by two consecutives reactions, an intermolecular nucleophilic substitution of ortho-iodo aniline with the enolate anion $\mathbf{2 a}$ induced by microwave irradiation followed by a condensation. The best isolated yield (49\%) of indole 15 was obtained at $100{ }^{\circ} \mathrm{C}$ (Scheme 6). This result agrees with that found in the previous examples in Table 2 , for intermolecular process.

\section{Conclusions}

The use of modern microwave heating devices proves valuable in the fine chemist and pharmaceutical chemistry offering a 
faster and safer synthetic methodology. In this report new $\mathrm{C}-\mathrm{C}$ bonds were obtained by $\alpha$-arylation of aromatic ketones and acetamides by a thermally induced $S_{\mathrm{RN}} 1$ reaction by microwave irradiation at moderate temperatures. This is the first report of microwave-induced $\mathrm{S}_{\mathrm{RN}} 1$ reaction in the aromatic system. The initiation step is proposed to take place by a microwave-induced thermal ET.

By comparison with the photoinduced procedures, the main disadvantage of the microwave-initiated reaction is the competitive reduction observed for intermolecular process, consequently the best substitution yields is about $60 \%$. On the other hand, the microwave-induced reaction shows as many advantages as simplicity, short times $(10 \mathrm{~min}$ of microwave irradiation compared with $120 \mathrm{~min}$ of photoirradiation), compatibility with substituents like $\mathrm{NO}_{2}, \mathrm{CN}, \mathrm{F}, \mathrm{Br}$, and a better performance in intramolecular reactions.

Thus, this process allows the synthesis of 2-aryl-1-phenyletanones (3a-k and $\mathbf{3 m}$ ) by $\alpha$-arylation of the enolate anion of acetophenones (2) with different haloarenes (1a-i). In addition, this methodology provides a simple way to achieve heterocycles as 1-methyl-3-phenylindolin-2-one (14) and 2-phenylindol (15) by intra- or intermolecular $S_{\mathrm{RN}} 1$ reactions, respectively, in a very fast reaction.

\section{Experimental section}

\section{Chemicals}

Potassium tert-butoxide ( $t \mathrm{BuOK}$ ), iodobenzene, bromobenzene, cyclohexanone, acetophenone, 1-p-tolylethanone, 1-(4-aminophenyl)ethanone, 1-(4-nitrophenyl)ethanone, 1-(4-chlorophenyl)ethanone, 1-iodonaphthalene, 1-bromonaphthalene, 2bromonaphtalene, 2-iodopyridine, 2-iodoaniline 1,2-diiodobenzene, 1,4-diiodobenzene, 1,2-bromo-iodobenzene, 1,4-fluoro-iodobenzene, 1,4-cyano-iodobenzene, 1,4-methoxyiodobenzene, and 1,4-iodo-nitrobenzene were all high purity commercial samples used without further purification.

DMSO absolute grade was used without further purification and stored over molecular sieves ( $4 \stackrel{\AA}{\circ}$ ). $N$-Methylanilides 13a-c were synthesized by standard procedures from the reaction between commercial 2-haloanilines and the corresponding acyl chloride in $\mathrm{CH}_{2} \mathrm{Cl}_{2}$ in the presence of pyridine. ${ }^{26} \mathrm{~N}$-(2-iodophenyl)- $N$-methyl-2-phenylacetamide (13a), ${ }^{27} N$-(2-bromophenyl)$N$-methyl-2-phenylacetamide (13b), ${ }^{28}$ and $N$-(2-chlorophenyl)- $N$ methyl-2-phenylacetamide $(\mathbf{1 3 c})^{27}$ present spectral data in good agreement with the literature.

The ketone enolate anion or the anion of $\mathrm{N}$-methylanilides was generated in situ by acid-base deprotonation using $t \mathrm{BuOK}$.

\section{General methods}

${ }^{1} \mathrm{H}$ and ${ }^{13} \mathrm{C}$ NMR spectra were recorded at 400.16 and 100.62 $\mathrm{MHz}$ respectively on a 400 spectrometer, and all spectra were reported in $\delta(\mathrm{ppm})$ relative to $\mathrm{Me}_{4} \mathrm{Si}$, with $\mathrm{CDCl}_{3}$ as solvent. Gas chromatographic analyses were performed with a flame-ionization detector, on $30 \mathrm{~m}$ capillary column of a $0.32 \mathrm{~mm} \times 0.25 \mu \mathrm{m}$ film thickness, with a $5 \%$ phenylpolysiloxane phase. GC-MS analyses were performed employing a $25 \mathrm{~m} \times 0.2 \mathrm{~mm} \times 0.33 \mu \mathrm{m}$ with a 5\% phenylpolysiloxane phase column. HRMS spectra were recorded on a GCT Premie orthogonal acceleration time-offlight (oa-TOF) GC mass spectrometer. Ionization was achieved by electronic impact $(70 \mathrm{eV})$ and detection set up positive mode.

\section{Representative experimental procedure}

The reactions were carried out in a $10 \mathrm{~mL}$ CEM Discover microwave glass vessel, filled with nitrogen and with a magnetic stirrer. The tube was dried under vacuum, filled with nitrogen, and then charged with dried DMSO $(2 \mathrm{~mL})$ and degassed. Next, for the $\alpha$-arylation of the haloarene, $t$ BuOK $(179 \mathrm{mg}, 1.55$ $\mathrm{mmol})$, acetophenone $(1.5 \mathrm{mmol})$, and aryl halide $(0.5 \mathrm{mmol})$ were added to the degassed solvent under nitrogen. For the intramolecular cyclization reaction halophenylacetamide $(0.5$ mmol) and $t$ BuOK $(112 \mathrm{mg}, 1.0 \mathrm{mmol})$ were added to the degassed solvent under nitrogen. Then, the reaction tube was heated by microwave irradiation.

Microwave-induced reactions were performed in a single mode instrument equipped with a noncontact infrared temperature sensor, direct pressure control system for measuring the pressure of the reaction vessel contents and a cooling system by compressed air. The sample vessels reach the selected temperature in about $30 \mathrm{~s}\left(\sim 2.5{ }^{\circ} \mathrm{C} \mathrm{s}^{-1}\right)$. Although, the maximum microwave power was set at $150 \mathrm{~W}$, after the initial heating pulse of maximum $100 \mathrm{~W}$ for $30 \mathrm{~s}$, the average applied power was about $1 \mathrm{~W}$ to keep the selected temperature (see ESI $\dagger$ for irradiation details). After $10 \mathrm{~min}$ of irradiation the device cooled the tube to $50{ }^{\circ} \mathrm{C}$ with compressed air above $1 \mathrm{~min}$ $\left(-0.5{ }^{\circ} \mathrm{C} \mathrm{s}^{-1}\right)$.

The average pressure in the vessel was $1.7 \mathrm{~atm}$ during the reaction time. After completion of the reaction, the vessel was removed from the microwave cavity and opened to the atmosphere. The reaction was subsequently quenched by addition of water $(30 \mathrm{~mL})$ and $\mathrm{NH}_{4} \mathrm{NO}_{3}$ excess, and the mixture was extracted with methylene chloride $(3 \times 20 \mathrm{~mL})$. The combined organic extract was dried over anhydrous $\mathrm{CaCl}_{2}$, and the products were quantified by GC or NMR by the internal standard method or isolated by silica gel chromatography from the crude product reaction mixture. Water layer was recovered to quantify the halide ions by potentiometric titration with an $\mathrm{AgNO}_{3}$ standard solution.

\section{Product isolation from a preparative scale reaction}

This reaction was performed following the representative experimental procedure using acetophenone $(7.5 \mathrm{mmol})$, tBuOK (7.75 mmol), and PhI $(2.5 \mathrm{mmol})$ in $10 \mathrm{~mL}$ of DMSO. After reaction and usual workup, the combined dried extract was first chromatographed on a silica gel short-column eluted first with $n$-pentane and second with $n$-pentane : ethyl ether (90:10). After evaporation the oily residue was distilled in a kügelrohr to separate the product 1,2-diphenylethanone (3a) from acetophenone. The substitution product 3a crystallizes at $0{ }^{\circ} \mathrm{C}$ with a small amount of $n$-hexane: $260 \mathrm{mg}$ (53\%); mp $53-55{ }^{\circ} \mathrm{C}$. 


\section{Products characterization}

All the products present in Table 2 were obtained following the general procedure, quantified by NMR or GC. Products 3a-k, 3m, 9a-c, 12, 14, and 15 are known compounds and present spectral data as shown in the literature, in agreement with the proposed structures. 1,2-Diphenylethanone (3a), ${ }^{29}$ 4-(2-oxo-2phenylethyl)benzonitrile (3b), ${ }^{30}$ 2-(4-methoxyphenyl)-1-phenylethanone (3c),$^{31}$ 2-(4-fluorophenyl)-1-phenylethanone (3d), ${ }^{31}$ 2-(4-nitrophenyl)-1-phenylethanone (3e),,$^{32}$-(naphthalen-1-yl)1-phenylethanone (3f), ${ }^{33}$ 2-(naphthalen-2-yl)-1-phenylethanone $(3 \mathbf{h}),{ }^{34}$ 1-phenyl-2-(pyridin-2-yl)ethanone (3i), ${ }^{35}$ 1-(4-methylphenyl)-2-phenylethanone (3j), ${ }^{36}$ 1-(4-aminophenyl)-2-phenylethanone $(3 \mathbf{k}),{ }^{37}$ 1-(4-chlorophenyl)-2-phenylethanone $(3 \mathbf{m}),{ }^{36} \quad 1$ (allyloxy)-2-iodobenzene (5), ${ }^{16} \quad$ 2-(2-iodophenyl)-1-phenylethanone (9a), ${ }^{21}$ 2-(2-bromophenyl)-1-phenylethanone (9b), ${ }^{38}$ 2-(4iodophenyl)-1-phenylethanone (9c), ${ }^{21}$ 2-phenylcyclohexanone (12) ${ }^{39}$ 1-methyl-3-phenylindolin-2-one (14), ${ }^{28}$ and 2-phenyl-1Hindole (15). ${ }^{32}$

\section{3-(2,3-Dihydrobenzofuran-3-yl)-1-phenylpropan-1-one (6)}

Following the general procedure, using $t$ BuOK $(179 \mathrm{mg}, 0.75$ $\mathrm{mmol})$, acetophenone $(0.75 \mathrm{mmol})$, and aryl halide 5 (0.25 $\mathrm{mmol}$ ), microwave irradiation at $60{ }^{\circ} \mathrm{C}$ for $10 \mathrm{~min}$ and then purification by radial chromatography (petroleum/ethyl ether, $8 / 2$ ) provided 6 as light yellow crystals (18 mg, 29\% yield).

${ }^{1} \mathrm{H}$ NMR (400 MHz, $\mathrm{CDCl}_{3}$ ) $\delta$ 7.94-7.92 (m, 2H), $7.57(\mathrm{tt}, 7.3$, $1.3 \mathrm{~Hz}, 1 \mathrm{H}), 7.46$ (tb, $J=7.6 \mathrm{~Hz}, 2 \mathrm{H}), 7.21(\mathrm{db}, J=7.3 \mathrm{~Hz}, 1 \mathrm{H})$, $7.14(\mathrm{tb}, J=7.7 \mathrm{~Hz}, 1 \mathrm{H}), 6.87(\mathrm{td}, J=7.4,1 \mathrm{~Hz}, 1 \mathrm{H}), 6.81(\mathrm{~d}, J=8$ $\mathrm{Hz}, 1 \mathrm{H}), 4.66(\mathrm{t}, J=8.9 \mathrm{~Hz}, 1 \mathrm{H}), 4.28(\mathrm{dd}, J=8.9,5.8 \mathrm{~Hz}, 1 \mathrm{H})$, 3.61-3.54 (m, 1H), 3.11-2.95 (m, 2H), 2.24-2.16 (m, 1H), 2.11-2.02 $(\mathrm{m}, 1 \mathrm{H}) .{ }^{13} \mathrm{C}$ NMR $\left(101 \mathrm{MHz}, \mathrm{CDCl}_{3}\right) \delta 199.5,160.0,136.8,133.2$, 130.1, 128.7, 128.4, 128.0, 124.5, 120.5, 109.7, 41.1, 35.3, 28.9. HRMS ESI ${ }^{+}\left[\mathrm{M}+\mathrm{Na}^{+}\right]$calcd for $\mathrm{C}_{17} \mathrm{H}_{16} \mathrm{O}_{2} \mathrm{Na}$ : 275.1043, found 275.1056 .

\section{2-(2-(Prop-1-enyloxy)phenyl)-1-phenylethanone (7)}

Following the general procedure, using $t$ BuOK $(179 \mathrm{mg}, 0.75$ $\mathrm{mmol})$, acetophenone $(0.75 \mathrm{mmol})$, and aryl halide 5 (0.25 $\mathrm{mmol}$ ), microwave irradiation at $60{ }^{\circ} \mathrm{C}$ for $10 \mathrm{~min}$ and then purification by radial chromatography (petroleum/ethyl ether, $8 / 2$ ) provided 7 as light brown crystals, (10 $\mathrm{mg}, 16 \%$ yield).

${ }^{1} \mathrm{H}$ NMR $\left(400 \mathrm{MHz}, \mathrm{CDCl}_{3}\right) \delta 8.08-8.06(\mathrm{~m}, 2 \mathrm{H}), 7.56(\mathrm{tt}, J=7$, $1 \mathrm{~Hz}, 1 \mathrm{H}), 7.56(\mathrm{tt}, J=7,1 \mathrm{~Hz}), 7.46(\mathrm{tb}, J=7.5 \mathrm{~Hz}, 1 \mathrm{H}), 7.27-$ $7.23(\mathrm{~m}, 2 \mathrm{H}), 7.02(\mathrm{td}, J=7.5,1 \mathrm{~Hz}, 1 \mathrm{H}), 6.96(\mathrm{dd}, J=8,1 \mathrm{~Hz}$, $1 \mathrm{H}), 6.34(\mathrm{dc}, J=6,1.7 \mathrm{~Hz}, 1 \mathrm{H}), 4.85(\mathrm{~cd}, J=6.8,6 \mathrm{~Hz}, 1 \mathrm{H}), 4.35$ $(\mathrm{s}, 2 \mathrm{H}), 1.60(\mathrm{dd}, J=6.8,1.7 \mathrm{~Hz}, 3 \mathrm{H}) .{ }^{13} \mathrm{C} \mathrm{NMR}\left(101 \mathrm{MHz}, \mathrm{CDCl}_{3}\right)$ $\delta$ 197.7, 155.2, 140.9, 136.9, 133.0, 131.3, 128.6, 128.5, 124.5, 122.6, 114.8, 107.6, 39.9, 9.3. HRMS ESI ${ }^{+}\left[\mathrm{M}+\mathrm{Na}^{+}\right]$calcd for $\mathrm{C}_{17} \mathrm{H}_{16} \mathrm{O}_{2} \mathrm{Na}$ : 275.1043, found 275.1047.

\section{Acknowledgements}

This work was supported by Consejo Nacional de Investigaciones Científicas y Técnicas (CONICET) and Agencia Nacional de Promoción Científica y Técnica (ANPCyT), Ministerio de Ciencia y Tecnología de la Provincia de Córdoba,
Argentina and SECyT-UNC. A.B.P. and D.A.C. are scientific members from CONICET, S.S.C. gratefully acknowledges the receipt of a fellowship from CONICET.

\section{Notes and references}

1 (a) Radicals in Organic Synthesis, ed. P. Renaud and M. Sibi, Wiley-VCH, Weinheim, vol. 1 and 2, 2001; (b) R. A. Rossi and A. B. Peñéñory, Curr. Org. Chem., 2006, 3, 437-451.

2 (a) R. A. Rossi, A. B. Pierini and A. B. Peñéñory, Chem. Rev., 2003, 103, 71-167; (b) A. B. Peñéñory, J. E. Argüello, Aromatic and Heteroaromatic Substitution by $\mathrm{S}_{\mathrm{RN}} 1$ and $\mathrm{S}_{\mathrm{N}} 1$ Reactions, in Handbook of Synthetic Photochemistry, ed. A. Albini and M. Fagnoni, Wiley-VCH, Weinheim, 2010, ch. 10, pp. 319-346; (c) R. A. Rossi and A. B. Peñéñory, in CRC Handbook of Organic Photochemistry and Photobiology, ed. W. M. Horspool and F. Lenci, CRC Press Inc., Boca Raton, 2nd edn, 2003, ch. 47, pp. 47-1-47-24; (d) R. A. Rossi, A. B. Pierini and A. N. Santiago, in Organic Reactions, ed. L. A. Paquette and R. Bittman, Wiley \& Sons, 1999, pp. 1-271.

3 H.-Q. Li, Y. Luo, P. C. Lv, L. Shi, C.-H. Liu and H.-L. Zhu, Bioorg. Med. Chem. Lett., 2010, 20, 2025-2028.

4 J. Sävmarker, J. Lindh and P. Nilson, Tetrahedron Lett., 2012, 51, 6886-6889.

5 H.-Q. Li, J.-Y. Xue, L. Shi, S.-Y. Gui and H.-L. Zhu, Eur. J. Med. Chem., 2008, 43, 662-667.

6 B.-Y. Ryu, S. Moon, I. Kosif, T. Ranganathan, R. J. Farris and T. Emrick, Polymer, 2009, 50, 767-774.

7 (a) G. L. Borosky, A. B. Pierini and R. A. Rossi, J. Org. Chem., 1992, 57, 247-252; (b) M. F. Semmelhack and T. Bargar, J. Am. Chem. Soc., 1980, 102, 7765-7774; (c) R. Beugelmans and M. Bois-Choussy, Heterocycles, 1987, 26, 1863-1871.

8 Liquid ammonia has a boiling point of $-33{ }^{\circ} \mathrm{C}$ and is extremely basic and corrosive. Inhalation may cause asphyxia.

9 R. G. Scamehorn, J. M. Hardacre, J. M. Lukanich and L. R. Sharpe, J. Org. Chem., 1984, 49, 4881-4883.

10 C. O. Kappe and D. Dallinger, Nat. Rev. Drug Discovery, 2006, 5, 51-63.

11 P. Vanelle, A. Gellis, M. Kaafarani, J. Maldonado and M. P. Crozet, Tetrahedron Lett., 1999, 40, 4343-4346.

12 L. Zink, M. D. Crozet, T. Terme and P. Vanelle, Tetrahedron Lett., 2011, 52, 6991-6996.

13 After microwave irradiation the reaction vessel reached 1.7 atm of pressure. To condense the possible gaseous reaction products, a tube was connected from the vessel to a nitrogen liquid tramp for the reaction of 1iodonaphthalene with anion 2a. Nevertheless, after releasing pressure only traces of naphthalene were detected in the tramp by GC-MS.

14 C. O. Kappe, B. Pieber and D. Dallinger, Angew. Chem., Int. Ed., 2013, 52, 1088-1094.

15 J. I. Bardagí, S. E. Vaillard and R. Rossi, Tetrahedron Lett., 2006, 47, 3149-3152.

16 S. E. Vaillard, A. Postigo and R. A. Rossi, J. Org. Chem., 2002, 67, 8500-8506. 
17 C. Costentin, P. Hapiot, M. Médebielle and J. M. Savéant, J. Am. Chem. Soc., 1999, 121, 4451-4460.

18 C. Costentin, P. Hapiot, M. Médebielle and J.-M. Savéant, J. Am. Chem. Soc., 2000, 122, 5623-5635.

19 L. C. Schmidt, J. E. Argüello and A. B. Peñéñory, J. Org. Chem., 2007, 72, 2936-2944.

20 J.-M. Savéant, J. Phys. Chem., 1994, 98, 3716-3724.

21 M. T. Baumgartner, L. B. Jiménez, A. B. Pierini and R. A. Rossi, J. Chem. Soc., Perkin Trans. 2, 2002, 10921097.

22 J. F. Bunnett and P. Singh, J. Org. Chem., 1981, 46, 50225025.

23 S. M. Crawford, P. G. Alsabeh and M. Stradiotto, Eur. J. Org. Chem., 2012, 6042-6050.

24 R. G. Compton, R. A. W. Dryfe, J. C. Eklund, S. D. Page, J. Hirst, L. B. Nei, G. W. J. Fleet, K. Y. Hsia, D. Bethell and L. J. Martingale, J. Chem. Soc., Perkin Trans. 2, 1995, 16731677, and references therein reported.

25 M. Meot-Ner, P. Neta, R. K. Norris and K. Wilson, J. Phys. Chem., 1986, 90, 168-173.

26 A. R. Fersht and W. P. Jencks, J. Am. Chem. Soc., 1970, 92, 5432-5442.

27 V. Rey, A. B. Pierini and A. B. Peñéñory, J. Org. Chem., 2009, 74, 1223-1230.
28 R. R. Goehring, Y. P. Sachdeva, J. S. Pisipati, M. C. Sleevi and J. F. Wolfe, J. Am. Chem. Soc., 1985, 107, 435-443.

29 J.-C. Hsieh, Y.-C. Chen, A.-Y. Cheng and H.-C. Tseng, Org. Lett., 2012, 14, 1282-1285.

30 A. Padwa, T. Brookhart, D. Dehm and G. Wubbels, J. Am. Chem. Soc., 1978, 100, 8247-8259.

31 K. Huang, G. Li, W.-P. Huang, D.-G. Yu and Z.-J. Shi, Chem. Commun., 2011, 47, 7224-7226.

32 T. Hering, D. P. Hari and B. König, J. Org. Chem., 2012, 77, 10347-10352.

33 A. Odedra, C.-J. Wu, T. B. Pratap, C.-W. Huang, Y.-F. Ran and R.-S. Liu, J. Am. Chem. Soc., 2005, 127, 3406-3412.

34 J. McEwen and K. Yates, J. Am. Chem. Soc., 1987, 109, 58005808.

35 M. A. Nazareno and R. A. Rossi, Tetrahedron Lett., 1994, 35, 5185-5188.

36 T. Miao and G.-W. Wang, Chem. Commun., 2011, 47, 95019503.

37 I. Ivanov, S. Nikolova and S. Statkova-Abeghe, Synth. Commun., 2006, 36, 1405-1411.

38 L. Ackermann and L. T. Kaspar, J. Org. Chem., 2007, 72, 61496153.

39 L. Li, P. Cai, Q. Guo and S. Xue, J. Org. Chem., 2008, 73, 35163522. 